\title{
Descrição e análise do acolhimento: uma contribuição para o programa de saúde da família
}

DESCRIPTION AND ANALYSIS OF EMBRACEMENT: A CONTRIBUTION TO FAMILY HEALTH PROGRAM

DESCRIPCIÓN Y ANALISIS DELACOGIMIENTO: UNA CONTRIBUICIÓN PARA EL PROGRAMA

DE SALUD DE LA FAMILIA

\author{
Lislaine Aparecida Fracolli ${ }^{1}$, Elma Lourdes Campos Pavone Zoboli ${ }^{2}$
}

\section{RESUMO}

O Programa de Saúde da Família prevê ações de saúde humanizadas, tecnicamente competentes e intersetorialmente articuladas, tornando fundamental "acolher". Este estudo objetivou identificar como se processa o "acolhimento" em Unidades de Saúde da Família, em São Paulo. Os sujeitos foram profissionais de saúde que realizavam "acolhimento" $e$ os dados foram coletados através de observações $e$ entrevistas. Os resultados apontaram que o "acolhimento" realiza uma escuta clínica, focalizada na queixa, com uma intervenção pontual, pouco resolutiva e não construtora de vínculo. É necessário repensar o "acolhimento", nos seus aspectos teóricos e práticos, para que este possa efetivamente se constituir em uma prática capaz de instaurar um modelo de saúde de "porta aberta" consoante com as diretrizes do SUS.

\section{PALAVRAS-CHAVE}

Saúde da família.

Saúde pública.

Tecnologia biomédica.

\begin{abstract}
The humanist and efficient healthcare required by the Family Health Program makes the "embracement" essential. This study aimed to identify how the

"embracement" was developed at Family Healthcare Services in Sao Paulo, SP. Brazil. The authors observed several "embracement" links and interviewed healthcare professionals. The results pointed out the clinical and biological focuses of the "embracement". They also showed that "embracement" resolution is limited and does not entail bounding. To make the healthcare services more accessible, according to the proposal of the National Health System, the theoretical and practical perspectives of the "embracement" must be reviewed.
\end{abstract}

\author{
RESUMEN \\ El Programa de Salud de la \\ Familia requiere atención \\ humanizada y técnicamente \\ competente, lo que hace \\ fundamental "acoger". Este \\ estudio tuvo como objetivo \\ identificar el proceso de \\ "acogimiento" en Unidades \\ de Salud de la Familia en São \\ Paulo, SP, Brasil. Los sujetos \\ fueron profesionales que \\ hacen el "acogimiento" y los \\ datos fueron recolectados por \\ medio de observaciones $y$ \\ entrevistas. Los resultados \\ mostraron que el \\ "acogimiento" realiza \\ escuch clínica enfocada en la \\ queja, con intervención \\ limitada, poco resolutiva y que \\ no construye vínculos. Es \\ necesario repensar el \\ “acogimiento”, en sus \\ aspectos teóricos y prácticos, \\ para viabilizar el modelo de \\ "puertas abiertas" como \\ proponen las directrices del \\ Sistema Único de Salud.
}

\author{
1 Enfermeira. Doutora \\ em Enfermagem. \\ Professora do \\ Departamento de \\ Enfermagem em \\ Saúde Coletiva da \\ Escola de Enfermagem \\ da USP(EEUSP). \\ lislaine@usp.br \\ 2 Enfermeira. Mestre \\ em Saúde Pública e \\ Bioética. Professora \\ do Departamento de \\ Enfermagem em Saúde \\ Coletiva da EEUSP. \\ elma@usp.br
}

PALABRAS CLAVE

Salud de la familia.

Salud pública.

Tecnología biomédica. 


\section{INTRODUÇÃO}

A estratégia do Programa de Saúde da Família (PSF) está estruturada na lógica de atenção básica à saúde, gerando novas práticas setoriais e afirmando a indissociabilidade entre os trabalhos clínicos e a promoção da saúde.

Para tanto, o PSF e os profissionais que nele atuam, necessitam desenvolver processos de trabalho que estabeleçam uma nova relação entre os profissionais de saúde e a comunidade e se traduzam, em termos de desenvolvimento de ações humanizadas, tecnicamente competentes, intersetorialmente articuladas e socialmente apropriadas. Apenas com ações desse tipo, o PSF conseguirá atingir os determinantes e condicionantes das condições de saúde-doença da população sob sua responsabilidade.

Isso exige dos trabalhadores e profissionais de saúde inseridos no PSF a incorporação de contínuas discussões acerca do seu processo de trabalho e da relação que travam com os usuários dos serviços de saúde, pois no encontro entre trabalhador e usuário

\begin{abstract}
operam processos tecnológicos (trabaIho vivo em ato) que visam a produção de relações de escutas e responsabilizações, que se articulam com a constituição de vínculos e dos compromissos em projetos de intervenção, que objetivam atuar sobre problemas/necessidades de saúde, em busca da produção de 'algo' que possa representar a conquista do controle do sofrimento (enquanto doença) e/ou a produção da saúde ${ }^{(1)}$.
\end{abstract}

Sem acolher e vincular não se concretiza a responsabilização e tampouco a otimização tecnológica das resolubilidades que efetivamente impactam os processos sociais de produção da saúde e da doença. A partir dessa afirmação os serviços de saúde, e mais especificamente o PSF, optaram por instituir espaços de acolhimento no seu processo de trabalho.

O acolhimento, nos serviços de saúde, tem sido considerado como um processo, especificamente de relações humanas; um processo, pois deve ser realizado por todos os trabalhadores de saúde e em todos os setores do atendimento. Não se limita ao ato de receber, mas se constitui em uma seqüência de atos e modos que compõem o processo de trabalho em saúde ${ }^{(2)}$.
O acolhimento é mais do que um fenômeno lingüístico, do discurso verbal, deve traduzir-se em intencionalidade de ações. Ele possibilita a captação das necessidades de saúde manifestadas pelo usuário e dispara imediatamente na instituição um processo de trabalho concretizado em ações que respondam à necessidades captadas ${ }^{(2)}$.

Entendido dessa maneira, o acolhimento tem a potencialidade de inverter a lógica de organização e funcionamento do serviço de saúde, partindo dos seguintes princípios:

- Atender a todas as pessoas que procuram os serviços de saúde, garantindo a acessibilidade universal. Assim, o serviço de saúde assume sua função precípua, de acolher, escutar e dar uma resposta positiva, capaz de resolver os problemas de saúde da população.

- Reorganizar o processo de trabalho, de forma que este desloque seu eixo central do médico para uma equipe multiprofissional - equipe de Acolhimento, que se encarrega da escuta do usuário,- comprometendo-se a resolver seu problema de saúde. A consulta médica é requisitada só para os casos em que ela se justifica. Desta forma, todos os profissionais de nível superior e ainda os auxiliares e técnicos de enfermagem participam da assistência direta ao usuário, aumentando enormemente o potencial de serviço da Unidade.

- Qualificar a relação trabalhador-usuário, que deve se pautar em parâmetros humanitários, de solidariedade e de cidadania. Essa é a argamassa capaz de unir solidamente os trabalhadores e usuários em torno de interesses comuns: a constituição de um serviço de saúde de qualidade, com atenção integral que atenda a todos e esteja sob o controle da comunidade ${ }^{(1)}$.

A partir dessas considerações pode-se afirmar que o acolhimento se constitui em instrumento potente para a reorganização da Atenção à saúde no PSF. Por ser uma tecnologia, tradicionalmente, pouco utilizada nos serviços de saúde, o presente trabalho teve por objetivo descrever como o acolhimento vem sendo desenvolvido e concebido nas Unidades de Saúde da Família_(USF), do município de São Paulo. 


\section{METODOLOGIA}

O estudo utilizou o materialismo histórico e dialético como referencial teórico e metodológico para a compreensão da práxis encontrada no acolhimento e esta foi analisada com base nos conceitos de processo de trabalho e processo de intervenção em saúde coletiva.

A compreensão do trabalho em saúde e suas práticas como práticas sociais traz o referencial da categoria trabalho para a saúde $^{(3)}$. Isto possibilita a compreensão de que estas práticas são determinadas pela finalidade social do trabalho e se referem a um projeto de ação que traduz uma dada concepção de processo saúde-doença e cuidado, ou seja, de uma perspectiva biológica e multicausal a finalidade do processo de trabalho em saúde será a normalização da atividade biomédica e da perspectiva da multidimensionalidade psicossocial, cultural; e biológica, portanto coletiva, a finalidade será a promoção da saúde e a emancipação dos sujeitos.

As intervenções em saúde coletiva consideram que a assistência à saúde é uma interferência consciente no processo saúdedoença de uma dada coletividade pelo conjunto dos profissionais de saúde com a população; objetivando o desenvolvimento de uma consciência crítica por parte dos usuários, para que estes se tornem sujeitos de suas próprias transformações. Essa consciência crítica é possível na medida em que são expostas as contradições da realidade, considerando também os pontos de vulnerabilidade e os momentos e formas de intervenção ${ }^{(4)}$.

O Programa de Saúde da Família na sua concepção teórica traz dentro de si as potencialidades para se transformar em uma proposta de intervenção em saúde que busca essa atuação mais emancipadora e transformadora dos sujeitos, e ao optar pela instituição do acolhimento, como um processo de trabalho nas Unidades de Saúde da Família, incrementa essa potencialidade inicial.

\section{Cenário de estudo, sujeitos $e$ procedimentos de pesquisa}

A pesquisa foi realizada em dez (10) USF,pertencentes ao Projeto QUALIS/
PSF, nas regiões norte e sudeste do município de São Paulo, no ano de 2000. As USF, nas quais o estudo foi realizado, estavam sob a responsabilidade do governo do Estado em parceria com a Fundação Zerbini.

O acolhimento, nas unidades de saúde estudadas, foi operacionalizado sob a forma de um atendimento específico, direcionado às pessoas que procuravam a USF e não tinham agendamento prévio. Estava organizado para possibilitar a escuta dos motivos que levaram o indivíduo a procurar o serviço de saúde naquele momento e dar uma resposta à sua necessidade. Era realizado em uma sala ou um local específico e os profissionais de saúde tinham uma escala para se revezarem no desenvolvimento dessa atividade.

Os sujeitos do estudo foram os profissionais de saúde (médicos, enfermeiros, auxiliares de enfermagem e agentes comunitários de saúde), que atuavam na realização do acolhimento nessas USF no período em que a pesquisa foi realizada.

Os instrumentos para a coleta de dados foram: um roteiro de observação (que visava descrever as ações realizadas pelo trabalhador ao realizar o acolhimento e descrever o ambiente físico e social do acolhimento)e em um roteiro de entrevista semi-estruturada (que procurava capturar as concepções que os trabalhadores tinham sobre o acolhimento).

Para a coleta de dados o pesquisador ficava dentro da sala onde se realizava o acolhimento e observava as ações desenvolvidas, durante um período de quatro (4) horas; a seguir realizava-se a entrevista com o trabalhador que havia sido observado. Os dados coletados foram organizados e analisados através do método de Discurso do Sujeito Coletivo (DSC) ${ }^{(5)}$ e do Fluxograma Analisadores $^{(6)}$.

O projeto de pesquisa foi aprovado pelo Comitê de Ética em Pesquisa da Escola de Enfermagem da USP, em outubro de 2000. As observações e entrevistas eram realizadas após consentimento livre e esclarecido dos trabalhadores e usuários, assegurando-se a liberdade de participação e recusa.
Descrição e análise do acolhimento: uma contribuição para o Programa de Saúde da Família 


\section{RESULTADOS E DISCUSSÕES}

\section{Descrição da organização do acolhimento nas unidades de saúde estudadas}

Nas Unidades de Saúde da Família (USF) estudadas, eram realizados, por dia, em média 40 acolhimentos, os quais duravam de três (3) a 15 minutos cada um. Estes eram realizados em salas arejadas e com mobiliário tipo consultório (cadeiras, mesa, maca) contudo, em algumas USF, a sala não era privativa para a atividade de acolhimento. A relação entre o trabalhador de saúde e o usuário do serviço, que se estabelecia no acolhimento, era marcada pela tensão, pois os usuários chegavam ansiosos e os trabalhadores buscavam atendê-los, de forma a acalmá-los, escutando-os com atenção. Entretanto, alguns trabalhadores, talvez premidos pela demanda, atendiam de maneira ágil, objetiva e pouco comunicativa.

Com relação aos profissionais que realizavam o acolhimento, encontrou-se que, de um modo geral, esta atividade fica a cargo das enfermeiras e das auxiliares de enfermagem, com a retaguarda do profissional médico. Em algumas unidades, é o agente comunitário de saúde se responsabilizava pelo acolhimento.

Com relação às formas de registro do acolhimento, observou-se que a maioria dos profissionais, das diferentes unidades, registrava o acolhimento como um atendimento, no prontuário do usuário. De forma geral, os registros enfocam o atendimento clínico. Alguns profissionais, além dessas fontes de registro, adotam um livro ou planilha próprio para o registro dos acolhimentos que realizam. Não foi identificado uso de protocolos como guias para o atendimento no acolhimento nas USF estudadas.

Os resultados revelaram que as USF estudadas consideram o acolhimento como uma estratégia para ampliar o acesso da população ao serviço de saúde. Poderiam ter dado qualquer outro nome para essa ação (recepção, triagem, etc), contudo ao denominar acolhimento mostram que gostariam de operar sob uma lógica diferente junto ao usuário. Embora exista essa perspectiva transformadora, o modo como o acolhimento vem sendo realizado precisa sofrer modificações, por exemplo: a falta de privacidade para a realização do acolhimento constitui uma prática que pode diminuir a potencialidade do mesmo, pois assegurar a privacidade é um dos elementos basilares da construção da relação de confiança entre o usuário e o trabalhador e esta relação de confiança é a base do acolhimento $^{(7)}$.

Os dados mostram ainda que o acolhimento, para ser realizado, prescinde de um ambiente físico que seja característico de uma intervenção clínica, isto é, salas com macas, aparelhos de aferição de sinais vitais, mesas ginecológicas, etc. Assim, este poderia ser realizado em espaços físicos que lembrem mais um ambiente informal de recepção, onde as pessoas possam se sentir acolhidas, não apenas através de suas queixas clínicas,(mensuráveis por aparelhos de aferição de Pressão Arterial, termômetros, Glicosímetros, etc.), mas através de suas necessidades de saúde (para as quais os trabalhadores de saúde parecem ainda não dispor de instrumentos específicos). A sala onde o acolhimento é realizado poderia trazer fotos das diversas atividades desenvolvidas pelos grupos de usuários que acontecem na USF, ajudando no estabelecimento de uma dinâmica relacional diferenciada, baseada em um tempo maior para ouvir o usuário.

Outro aspecto importante é o número de acolhimentos realizados. Entende-se que o acolhimento é uma forma de ampliar o acesso da população ao serviço contudo, as demandas atendidas deveriam ser objeto de discussão das equipes e da gerência das USF, para que as mesmas possam, a partir da demanda, repensar a oferta de serviços, os programas prioritários e a organização do trabalho das Equipes de Saúde da Família (ESF).

Entendendo que o acolhimento se constitui em uma prática $\mathrm{ESF}_{2}$ seria adequado que todos os profissionais da ESF o realizem, pois acolher, embora incorpore a dimensão clínica, não se restringe a ela. Assim, trabalhadores que não operam, no cotidiano de seu trabalho, com o saber clínico podem reaalizar acolhimento, ainda que para essa atuação precise de algumas discussões, na equipe, dos casos acolhidos. Neste sentido, a inserção do profissional médico nessa atividade não deve limitar-se á retaguarda.

Com relação ao registro do acolhimento, esta é uma parte importante, uma vez que é a 
partir dele que a equipe pode compartilhar informações sobre o usuário, identificar aspectos familiares que possam estar intervindo no seu processo saúde-doença e possibilitar a continuidade e o acompanhamento da atenção prestada. Assim, observa-se que o instrumento de registro precisa ser ampliado no sentido de retratar para além das características biológicas e individuais da queixa. Além do mais, não se pode esquecer que um prontuário completo configura um dos direitos dos usuários.

\section{O Processo de trabalho desenvolvido no "acolhimento"}

As ações que compõe o processo de trabalho desenvolvido no acolhimento foram: identificar o problema do usuário e propor uma resposta para o que ele está sentindo; realizar encaminhamento dos usuários para outros serviços, como pronto socorro, consulta médica, etc.; realizar anamnese dirigida para a queixa; realizar triagem para encaminhamento imediato ou mediato, segundo vagas preestabelecidas e gravidade da queixa; realizar exame físico e verificar os sinais vitais, com enfoque na queixa; supervisionar o auxiliar de enfermagem quando este realiza o acolhimento; supervisionar a porta de entrada do posto; distribuir senhas para atendimento; realizar consulta médica ou de enfermagem; trocar prescrições de medicamentos; realizar orientações sobre saúde; realizar curativos; administrar medicamentos; realizar escuta humanizada do usuário para atender sua necessidade; dar apoio às pessoas que procuram o serviço.

A análise dessas ações e sua articulação ao processo de trabalho desenvolvido, através do fluxograma analisador ${ }^{(6)}$, permite realizar as seguintes afirmações: a terminalidade dos acolhimentos é a consulta médica (imediata ou mediata); o momento de escuta do usuário se caracteriza pela busca de informações eminentemente clínicas, quando se identificam informações de outras dimensões (social, cultural ou psicológica), estas não são utilizadas e, muitas vezes, nem mesmo consideradas; as queixas apresentadas pelos usuários, com certa freqüência, são exageradas, já que a entrada na USF só é possível através de uma queixa clínica (e da gravidade dessa queixa); as ações desenvolvidas durante o acolhimento condicionam a volta das pessoas a esse atendimento; as avaliações reali- zadas pelos profissionais são eminentemente clínicas, não existindo uma avaliação das queixas dos usuários, segundo categorias sociais ou programáticas; o momento da anamnese opera com um conjunto de ações que tem por objetivo a identificação dos limites para a prática de quem implementa o acolhimento, ou seja, o que da queixa pode ser resolvido pelo trabalhador naquele momento e o que deve ser encaminhado, porém não fica claro como esses limites são definidos uma vez que não existem protocolos formalizados; falta uma abordagem da família.

A organização do trabalho, ainda está centrada na consulta médica, operando com o conhecimento clínico-biológico de cunho fisio-patológico, no qual as tecnologias leve, ou seja as tecnologias de relações, assumem um papel secundário em relação às tecnologias leve-dura, ou seja os saberes instituídos. O uso de tecnologias leve, por parte dos trabalhadores no acolhimento, quando ocorre, é de forma limitada, ou seja, não incorpora uma intervenção sobre os determinantes e condicionantes do problema, que os fez procurar o serviço de saúde. O trabalhador, que realiza o acolhimento, tem dificuldades para lidar com problemas e necessidades no âmbito da saúde mental, isto é, apesar da importância atribuída às tecnologias leve-dura, há um despreparo nesse aspecto com relação á área temática de saúde mental.

Da forma como está sendo implementado, o acolhimento não se constitui em um instrumento para autonomizar o usuário a enfrentar seu processo saúde-doença como protagonista e co-responsável (em parceria com o trabalhador de saúde) do mesmo.

O acolhimento se apresentou, nesse estudo, como um modelo clínico-biomédico, no qual o atendimento é realizado com base no modelo queixa-conduta e como uma forma de triagem apoiada em práticas conflitantes (normalização administrativa versus gravidade/ risco biológico). As ações de encaminhamento não utilizam a potencialidade de "outras" intervenções oferecidas pelo PSF, como grupos educativos, grupos de caminhada, entre outros, e se pautam na derivação para consulta médica. Não relacionam o perfil epidemiológico para desenvolverem ações coletivas, que possam impactar nas demandas individuais por saúde.
Descrição e análise do acolhimento: uma contribuição para o Programa de Saúde da Família

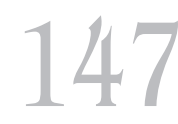

Rev Esc Enferm USP 2004; 38(2):143-51. 
Lislaine Aparecida Fracolli Elma Lourdes C.P. Zoboli
As ações elencadas como constitutivas do acolhimento apontam para a possibilidade de caracterizar o acolhimento como uma atividade organizadora da porta de entrada da USF. Dentro desta lógica, o acolhimento corre o risco de se transformar em, simplesmente, mais uma atividade, mais uma tecnologia com instrumentos, lugares, agentes e saberes próprios, enfim mais um serviço oferecido pela USF e não uma forma de mudar as relações entre trabalhadores e usuários e reorganizar o serviço para oferecer mais qualidade na atenção à saúde.

Um outro aspecto a ser discutido, referese ao fato de que ao se transformar o acolhimento em um serviço específico, corre-se o risco destas USF se tornarem um grande Pronto Atendimento (PA). Não se quer, com isso, anular a validade do PA como um recurso $a$ mais para abordar o usuário, mas o que se deseja é alertar para a não redução da USF a um lugar aonde só se faz PA.

$\mathrm{O}$ acolhimento deve ser traduzido como uma relação

humanizada, acolhedora, que os trabaIhadores e o serviço, como um todo, têm que estabelecer com os diferentes tipos de usuários que a eles aportam ${ }^{(1)}$

Para tanto é necessário, que os trabalhadores e os serviços de saúde realizem uma reflexão sobre as relações que têm estabelecido com os usuários, especialmente quando ela se torna mais tensa, como nas portas de entrada dos serviços de saúde, onde a distribuição de senhas impõe limites administrativos ao acesso e pode levar a um distanciamento entre trabalhador e usuário, que resulta na não produção do que é direito de todos (usuários e cidadãos): um atendimento humanizado, fundamental como parte do processo de criação do vínculo e do processo terapêutico que deve visar a autonomização do usuário(1).

Com isto, não se pretende invalidar as medidas administrativas que objetivam a organização das USF, mas se quer alertar para o risco de que estas se convertam em pautas rígidas a ordenar condutas e impedir o acesso ao sistema de saúde. Antes de implementar tais medidas deve-se perguntar pelo seu propósito, se este não incluir a melhoria da capacidade dos trabalhadores na condução das questões essenciais envolvidas na resolução das necessidades e problemas de saúde do usuário, deve-se ter cautela na sua adoção.

Para humanizar a relação entre trabalhador e usuário, nos serviços de saúde, não basta restringir-se a escuta e ao respeito, é preciso ultrapassar essa visão afetuosa do relacionamento, a partir da construção de um processo de gestão do trabalho pautado na autogestão e na responsabilização do trabalhador de saúde com seu objeto de trabalho, a vida e o sofrimento das pessoas e da coletividade $^{(1)}$.

Outra questão que merece ser discutida num estudo sobre acolhimento, refere-se à resolubilidade do mesmo. Para que uma ação seja considerada resolutiva esta, não necessariamente, deve se limitar a ter uma conduta clínica mas, além disso, coloca a possibilidade de usar toda tecnologia leve e leve-dura que se dispõe para eliminar as causas reais do problema do usuário. Assim, ações como consultas médicas ou de enfermagem, curativos, orientações, dentre outras, baseadas na clínica, por si só, não são suficientes para dar todas as respostas às várias dimensões que compõem os problemas e as necessidades de saúde das pessoas, sendo essencial trabalhar com ações coletivas, que evocam a intersetorialidade e uma rede de referência e contra-referência eficiente.

\section{A percepção dos trabalhadores sobre o acolhimento}

Partindo do pressuposto que todo processo de trabalho tem em si uma intencionalidade e uma dada concepção de processo saúde-doença, buscou-se nesse estudo identificar as concepções e as propostas de ação dos trabalhadores das ESF ao realizarem o acolhimento.

Os resultados das entrevistas, expressos no discurso dos sujeitos coletivos apontaram para uma divergência entre os trabalhadores de saúde, que realizavam acolhimento nas diferentes USF. Assim, um grupo manifestava a necessidade de rever as ações do acolhimento e outro grupo achava que isso não era importante, considerando que se havia algo que deveria ser modificado eram os usuários e o sistema de saúde.

Esses posicionamentos foram classificados e expressos a partir dos seguintes temas: 
- São necessárias modificações no acolhimento, com relação ao tempo, à proximidade com o usuário e a que profissional compete sua realização.

Deveria ficar mais tempo. Deveria estar mais próximo, não ficar tanto no consultório, ficar fazendo exame físico e tomando as providências, a gente deveria ficar rodando, ver quem é que está precisando. Se pudesse quem deveria ficar realmente atendendo essa necessidade era a enfermeira.

- O acolhimento não precisa de modificações, está bem estruturado.

Já tem bem fechado a questão do acolhimento. O acolhimento já tem o máximo, não tem mais o que propor para melhorar o acoIhimento. Ele está bem estruturado como está, porque consegue atender as necessidades dos pacientes no programa.

- O acolhimento não precisa de modificações, quem precisa de modificações é a rede de serviços de saúde.

Não proporia ações para o acolhimento em si, porque o acolhimento é o que é, é isso mesmo, escutar o paciente e ver o que você pode fazer né, o que você pode dar de resposta. Mas proporia uma reorganização do atendimento como um todo, você organizar sua demanda programática, ter um controle mais eficaz dos seus hipertensos, diabéticos, porque aí essa pessoa não vai tá aparecendo tanto na unidade de sopetão para você atender de última hora. Teria que ter mais postos, assim como esses projetos de médico da família nas comunidades e diminuir o número de famílias, aí você tem condição de atender de uma forma diferente tudo, inclusive o acolhimento.

- O acolhimento não precisa de modificações, o usuário é que deve ser preparado sobre seus direitos.

Essas entidades, postos de saúde, escola, esses grupos que existem em comunidades, nos bairros deveriam preparar a população sobre essas coisas a que ele tem direito o que ele não tem.

A análise dos discursos revelou que, mesmo quando admite a necessidade de modificações no acolhimento, o trabalhador de saúde não consegue apresentar propostas concretas para essa reformulação, o máximo que ele consegue sugerir é a necessidade de reorganiza- ção da rede e do processo de trabalho da USF, é como se o processo de trabalho dele (trabalhador) fosse totalmente instituído por essas instâncias. Tal fato, sugere uma indisponibilidade dos trabalhadores a questionarem (e transformarem) o acolhimento através da transformação da sua prática. Por outro lado, considera-se positiva a visão ampliada na avaliação do acolhimento que os trabalhadores apresentam, identificando sua inter-relação enquanto porta de entrada do sistema de saúde, com os diferentes equipamentos sociais e de saúde, presentes na área de abrangência da USF e não se limitando a discutir o acolhimento em si, apenas como uma prática técnica.

Na percepção dos trabalhadores, o $a c o-$ lhimento deveria incorporar mais a realização de ações de prevenção, de educação, de conscientização e de orientação, o que, na opinião dos trabalhadores, é dificultado pelo excesso de queixas clínicas que aparecem no acolhimento.

Outra questão que surgiu, na percepção dos trabalhadores, foi a necessidade de normalização do acolhimento, com a delimitação de horário, número de vagas e área de procedência, considerando ainda a urgência/emergência clínica da queixa. Alguns entrevistados entendem que precisam de melhorias nas condições de trabalho para realizar o acolhimento, como mais tempo, menos pessoas para atender e melhor espaço físico.

A análise das percepções trazidas pelos trabalhadores sobre seu trabalho indica que, ao proporem uma normalização para o acolhimento, estes esperam que os usuários se enquadrem às normas institucionais, especialmente as relativas à área de responsabilidade e horário, sendo compreensivos com a limitação do número de vagas. Entende-se que é mais simples normalizar a entrada dos usuários na USF com a lógica da delimitação adscrição das áreas, do que propiciar discussões entre as diferentes equipes que, levando a uma democratização do conhecimento relativo às necessidades/problemas da área de abrangência, facilita a articulação entre totalidade, particularidade e singularidade na intervenção no coletivo. Outra questão que se apresenta é a necessidade de desfocar a atenção da queixa (biológica) para se construir uma lógica centrada no usuário.

Os resultados permitem visualizar que o acolhimento ainda é uma ação de saúde pou-
Descrição e análise do acolhimento: uma contribuição para o Programa de Saúde da Família 
Lislaine Aparecida Fracolli Elma Lourdes C.P. Zoboli co clara para os trabalhadores das ESF e para a USF. É possível observar que embora os conceitos sobre acolhimento estejam apreendidos, a sua operacionalização ainda é uma caixa preta para as ESF. Isso pode ser observado quando vemos o acolhimento traduzido em ações instituídas como triagem, consulta agendada, encaminhamento, normas de acesso, etc. De qualquer forma buscar operacionalizar o conceito de acolhimento é uma maneira de produzir ruídos no processo de trabalho da USF, na direção da construção de uma nova modalidade de assistência à saúde.

\section{CONSIDERAÇÕES FINAIS}

O presente estudo teve como objetivo descrever o acolhimento, no sentido de identificar a forma como este vem sendo implementado pelas ESF no PSF.

Este trabalho pôde identificar alguns aspectos críticos que devem ser pensados e internalizados, pelos trabalhadores das ESF, a fim de que o acolhimento possa se inserir como uma prática, que supere o modelo biológico-hegemônico em direção a uma centralidade do usuário, que é sujeito e fim do processo assistencial.

Com este estudo foi possível concluir que a escuta que se tem feito do usuário, que procura o serviço no acolhimento, é uma escuta clínica, focalizada nas queixas e, portanto, a intervenção realizada é pontual, pouco resolutiva e não construtora de vínculo, contribuindo pouco para a autonomização do usuário e para a implementação de práticas de saúde que extrapolem a abordagem de natureza clínica e individual.

Pode-se identificar, também, que o acolhimento tem dificuldades no estabelecimento de escutas ampliadas, pois estas fazem aflorar problemas e necessidades que não podem ser resolvidos apenas no âmbito do serviço de saúde e tornam, assim, imprescindível que sejam incorporadas ás práticas das USF uma articulação intersetorial, ou seja, reconhecer e buscar parcerias externas à unidade e ao setor saúde. Isso significa estabelecer um diálogo efetivo com os hospitais, laboratórios e outros serviços de diagnose e terapia, com vistas a estabelecer interações de referência e contra-referência; além de estabelecer relacionamentos profissionais e de ajuda com as associações comunitárias; os sindicatos e as escolas, dentre outros.
Uma vez que o PSF se propõe a ser a estratégia do Ministério da Saúde para a reorganização da Atenção Básica, é imprescindível que os profissionais de saúde aprendam a reconhecer quais são os problemas e as necessidades de saúde dos indivíduos e famílias sob sua responsabilidade, e ao reconhecer esses problemas/necessidades, consigam traçar uma proposta de intervenção para os mesmos, identificando que as ações de saúde que estão sob sua responsabilidade atendem a uma pequena parcela dos problemas/necessidades presentes e que a outra parcela precisa ser atendida, caso contrário, o problema não estará resolvido. É nesse momento que se faz necessário a articulação intersetorial.

As ESF precisam incorporar a idéia de que sua responsabilidade não se limita às quatro paredes da USF e que causar impacto nos problemas significa trazer respostas reais que alteram o quadro de saúde da sua área de responsabilização.

Organizar um serviço de saúde significa montar algo que altere as condições de saúde do território, interferindo positivamente no modo de produção dos riscos e dos sofrimentos. $\mathrm{O}$ grande desafio é articular os diferentes setores de produção de uma USF em uma gestão compartilhada que responda pelo acesso dos usuários com acolhimento, vínculo e resolubilidade.

Assim, implementar o acolhimento requer que além de instituir uma USF de porta aberta, que responda as demandas da comunidade, se institua um relacionamento com os outros serviços de saúde da área. A análise dos dados obtidos com o presente estudo nos permitem concluir que as ESF ao realizarem o acolhimento entendem que os instrumentos de trabalho que possuem e a maneira como abordam os problemas de saúde são insuficientes para dar assistência de qualidade à população sobre sua responsabilidade. Contudo ao refletirem sobre a forma de superação desse problema, não conseguem redirecionar sua prática rumo à construção do novo. Operam com concepções de processo saúde-doença pouco adequadas para o trabalho com comunidades e se esquecem, muitas vezes, das propostas do SUS.

O presente estudo pretendeu dar visibilidade às práticas que vêm sendo desenvolvidas no acolhimento, no sentido de alertar aos profissionais, gestores e pesquisadores sobre a necessidade de se investir esforços na implementação dessa proposta nas unidades de saúde de um modo geral. 
(1) Franco TB, Bueno WS, Merhy EE. O acolhimento e os processos de trabalho em saúde: o caso de Betim, Minas Gerais, Brasil. Cad Saúde Pública 1999; 15(2):345-53.

(2) Matumoto S. O acolhimento: um estudo sobre seus componentes e sua produção em uma unidade da rede básica de serviços de saúde. Ribeirão Preto. [dissertação]. Ribeirão Preto(SP): Escola de Enfermagem de Ribeirão Preto/ USP; 1998.

(3) Schraiber LB. Ciência, trabalho e trabalhador em saúde: contribuição de Ricardo Bruno Gonçalves para a compreensão da articulação entre saber, prática e recursos humanos. Divulgação Saúde Debate 1996; (14):7-9.
(4) Egry YE. Saúde coletiva: construindo um novo método em enfermagem. São Paulo: ÍCONE; 1996.

(5) Lefèvre F, Lefèvre AMC, Teixeira JJV. organizadores. O Discurso do Sujeito Coletivo: uma nova abordagem metodológica na pesquisa qualitativa. Caxias do Sul: EDUCS; 2000.

(6) Merhy EE; Onocko R, organizadores. Agir em saúde: um desafio para o público. São Paulo: Hucitec; 1997

(7) Sacardo DP. Expectativa de privacidade segundo pessoas hospitalizadas e não hospitalizadas: uma abordagem bioética. [dissertação]. São Paulo (SP): Faculdade de Saúde Pública da USP; 2001.
Descrição e análise do acolhimento: uma contribuição para o Programa de Saúde da Família 